\title{
Assessment of the competitiveness of industrial companies and methods for assessing the quality of construction products
}

\author{
Olga Safonova ${ }^{1, *}$ and Lyudmila Tatarnikova ${ }^{1}$ \\ ${ }^{1}$ Irkutsk National Research Technical University, ul. Lermontova, d. 83, 664074, Irkutsk, Russia
}

\begin{abstract}
The model of a quality management system based on international standards ISO 9000 series is recognized in all the world. The aim of the article is to show the competitive advantages of a construction company in the modern market by improving its quality and product management system. We consider the implementation of the provisions of international standards ISO 9000 series as an effective solution to the problem. Quality improvement is a continuous work aimed at improving the technical level of product quality, quality of its manufacture, improving production elements and the quality system itself. The authors of the article give a specific method for improving the enterprise quality management system with a developed sequence. A risk-based approach to creating an enterprise quality management system was also considered. The main research methods in assessing the technical condition of certain building materials are differential, integrated and mixed methods. The authors show the calculation procedure using these methods, as well as the main results of their application. Then, the article provides a methodology for calculating the level of product quality, which is evaluated by a set of indicators, which do not include economic indicators.
\end{abstract}

\section{Introduction}

Modern construction companies operate in constantly changing market conditions. Only those companies that can quickly adapt to changes in the external environment can survive in the competition. In this regard, the quality management system should be flexible and quickly "customizable" for changing requirements of the parties interested in the enterprise. Only such a management system can become a useful tool in the hands of enterprise management.

It is necessary to increase the level of product quality in modern market conditions. Quality is becoming one of the decisive factors in increasing production efficiency at a modern enterprise in the construction industry and the intensive development of the economy as a whole. Also, the production of low-quality products causes great economic damage to individual enterprises, the construction industry and the national economy.

\footnotetext{
* Corresponding author: olyastefanovskaya@mail.ru
} 
Quality determines the level of competitiveness of a modern enterprise in the face of increased competition for markets.

That is why improving product quality is a critical goal that can increase production efficiency. Production efficiency, in turn, is determined by the ratio of the results obtained and production costs.

Product quality is determined by the generalized properties of its production (reliability, durability, maintainability), which can satisfy certain needs for further operation.

Product quality is characterized by a number of properties, and properties are characterized by indicators that quantitatively characterize one or more properties of this product.

The quality of products in the architectural or construction industry is characterized by an indicator of scientific and technological progress and a production culture in this industry. The relevance of the quality of construction products occupies a special place in connection with the need to increase the competitiveness of products on the market. Ensuring and improving the quality level of products in the construction industry is a multifaceted task. Its solution consists in improving structures and their components, in the use of new materials and in the automation of technological processes.

Product quality is a relative concept and can be quantified by comparison with basic products of the same purpose. The relative characteristic of product quality, based on its comparison with the corresponding set of basic indicators, is called the level of product quality. Values characterizing the properties of product quality are called quality indicators. They can be absolute, relative or specific.

The criterion for the level of product quality is an integral quality indicator, which identifies the ratio of the useful total effect of the operation of the product and the total cost of its manufacture. Product quality management is carried out by systematic monitoring of compliance of quality indicators with standards, technical specifications, regulatory documents, targeted impact on the quality of documentation, equipment, tools, materials, components and the manufacturers' qualifications $[1,2]$.

The quality problem of such an industry as architecture and construction is acquiring a special role at the moment. The manufacture of quality products is the main way to increase competitiveness in world markets, and it is also one of the main components of economic progress. A special place in the problem of ensuring the quality of products in the construction industry is occupied by new progressive design developments and studies.

The quality management system in construction is a product of our time. This is a special tool for ensuring high-quality execution of construction work and eliminating all sorts of risks that could threaten the safe operation of constructed facilities.

Construction is traditionally one of the largest sectors of the economy of any country, which solves many tasks of a state nature, namely, GDP growth. That is why it is important that the industry operates efficiently and reliably. This is only possible with a quality management system [3].

The quality management system in construction is a set of processes of a construction company that are created to implement a quality policy through management, planning, provision and improvement of quality.

The fundamental document of the system is a quality policy that defines the objectives of the functioning and construction of a quality management system in construction, as well as the duties and responsibilities of senior management to achieve the goals.

The first stage in the development and implementation of a quality management system in construction is the selection of its model. Next, there is a comparison of the activities of a construction company with the principles of this model. After that, documentation is developed and implemented. The quality management system is certified to increase the 
efficiency of all processes. The last step is the continuous improvement of the organization's activities based on continuous process improvement.

The main fundamental documents for the creation and implementation of a quality management system in construction are ISO standards 9000 and 14000.

It is also important that in recent years in developed countries ensuring product quality is no longer the concern of individual firms. This is becoming a nationwide problem. So, this problem is considered as the most important national task in Japan. The United States organizes national quality months. The Swedish government conducts nationwide campaigns for the quality of building products. And the Netherlands develops a nationwide five-year plan to improve the quality of products and parts of the construction industry. Developed countries pay special attention to the quality of products due to the conditions, forms and methods of the intensified competition for sales platforms for building materials. Most countries spend a lot of effort to improve the quality of products and determine their prestige and position in the global market in the fight against competitors [4].

The problem of ensuring the quality of construction products is particularly relevant in Russia. This problem arose even in a policy economy, when all work to ensure and improve product quality was planned and controlled by the state. However, at the same time, the requirements of consumers were not important, and the quality of the products was evaluated according to the requirements of regulatory documents, which most often did not meet the requirements of customers. The monopolistic position of manufacturers and the lack of a powerful market incentive for growth in the form of competition do not give interest in improving the quality of products and in spending additional financial resources for these purposes. In this regard, the commodity shortage exacerbated the situation with product quality, when demand increasingly exceeded supply, and the consumer was deprived of choice and was ready to buy goods of any quality and at any price. That is why the problem of ensuring product quality is important and serious for the development of the country's economy, its progress and prosperity.

Market relations have exacerbated the problem of quality and competitiveness of products by construction enterprises and factories. An effective means of solving this problem is the implementation of the provisions of international standards ISO 9000 series, which reflect the world experience in ensuring product quality, and the main emphasis is on measures to guarantee a stable production.

To achieve this goal, it is necessary for the manufacturing company to keep under control all the technical, administrative and human factors that affect the quality of the products. To achieve the goals defined by the company's policy in the field of quality, it is necessary to develop and implement a quality system that covers 2 interrelated aspects:

1) consumer needs and expectations;

2) requests and interests of the organization.

Quality improvement is a constant work aimed at improving the technical level of product quality, the quality of its manufacture, improving production elements and the quality system. The process of improving the quality system is recommended in the following sequence:

- determine the direction of improvements and the means for their implementation;

- explore the characteristic features of the problem;

- analyze the collected information, outline the changes and, if necessary, experimentally check the changes;

- make changes to the improvement object;

- analyze the functioning of the object of improvement after making changes;

- bring the found improvement solutions to the documents.

ISO 9000 "General quality management and quality assurance standards. Guidelines for selection and application" defines key terms, gives an interpretation of contractual terms, 
types of standards and contains the basic principles for the implementation of quality management policies. It establishes and shares the rules for the use of quality assurance models associated with the contract (ISO 9001, ISO 9002, ISO 9003), formulates the three main tasks of the manufacturer in the field of quality, namely [5]:

1) to achieve and maintain product quality at a level that is able to ensure continuous satisfaction of consumer goals;

2) to provide management with confidence that the required quality is achieved and maintained at a given level;

3 ) to provide the consumer with confidence that the intended quality of the delivered products is being achieved or will be achieved; confidence may mean providing the required evidence if the contract provides this.

Particular attention in the ISO 9000 standard should be given to the conclusion of a contract, which, as a rule, is preceded by an assessment of the existing quality system at the enterprise in order to determine the ability of the supplier to meet the requirements of the standards and additional technical requirements for products or services that are established in the technical conditions of the contract.

A risk-based approach to the creation of a QMS is used to develop the international standard ISO 9001: 2015. This is one of the key changes in the new version of the standard. The fundamentals of risk management in the updated version of the standard are integrated into the quality management system as a whole, and taking risks into account when making decisions turns preventive actions into part of the process approach. Activities related to risk management provide the basis for improving the effectiveness of the quality management system, achieving better results and preventing adverse effects. The organization needs to identify the risks and opportunities to be considered, as well as plan and implement actions to reduce them and evaluate the effectiveness of these actions [6].

But not all organization processes have the same risk level in terms of their impact on the organization's ability to achieve their goals, as well as the consequences of inconsistencies in the processes, products, services or system are not the same for different organizations. Some organizations have minor consumer implications for the supply of inappropriate products or the provision of inappropriate services. However, in other cases, inconsistencies can lead to negative consequences and even fatal outcomes. Therefore, the risk-based thinking means the need for a quantitative consideration of risk in determining the rigor and depth of the approach to planning and managing the quality management system, its processes and activities.

The text of the standard implies the application of a risk-based approach at all stages of the functioning of the quality management system.

Risk should be understood not only as a negative phenomenon, but also as an opportunity to find areas for improving processes. ISO 9001: 2015 does not require a complete, formal risk assessment with the completion of "risk registers" or any other documents. GOST R ISO 31000-2010 "Risk management. Principles and Guidelines" can be called a useful guide to risk-based decision-making methods.

Thus, interest in applying a risk-based approach to building a QMS will increase due to the mandatory transition to a new version of the ISO 9001: 2015 standard, and the developed methodology and tools can be widely used. Improving the competitiveness of the construction organization using risk-oriented thinking is achieved by improving management, ensuring high quality products and services, increasing trust and customer satisfaction. 


\section{Materials and Methods}

The need to assess the level of quality of industrial products arises from its planning, certification and control.

It is necessary to use a differential, integrated and mixed method to assess the technical condition of certain building materials. Expert assessments are needed when it becomes difficult to evaluate quality with quantitative indicators. Differential assessment consists in calculating individual indicators using the formula [7]:

$$
Y K i=\frac{P i}{P i \text { iáŕç }}
$$

where $\mathrm{Pi}$ - indicator of the quality parameter of the evaluated material; Piáŕç corresponding quality indicator of the base sample of the same material.

If the quality score has confines (Pd'đi), then the quality level is determined by the formula:

$$
O K i=\frac{p i-p l d i}{\text { piaac }- \text { pldi }}
$$

All quality indicators are divided into 2 types for one or another type of material: main and secondary. The technical level of the material or product is below the base, if at least one of the main indicators is lower than the same basic indicator. If the indicators are difficult to divide into main and secondary, then the assessment is carried out according to complex or mixed quality assessments.

We can use a single indicator (P), integral indicator (Pčí), weighted average arithmetic $(\mathrm{U})$ or geometric $(\mathrm{V})$ indicator of quality as an integrated measure:

$$
U=\sum_{i=1}^{n} \mathrm{miu} \cdot P i ; V=\prod_{i=1}^{n}(P i) \mathrm{miv}
$$

where miu miv, - quality indicator weight parameters; $n$ - number of indicators.

Some indicators are combined into groups for evaluation by a mixed method, while others are not combined. Then they are compared with group or single indicators of the base case.

The nomenclature of quality indicators is established based on the objectives of this assessment and taking into account the significance of the quality indicators specified in the documents for this type of product or material. In this case, it is necessary to take into account international, national foreign and domestic quality standards, documentation for the supply of materials, catalogs, prospectuses and standards of manufacturers of this type of material, patent, competitive and economic documentation.

\section{Results}

The level of product quality, which is evaluated by a set of indicators, which do not include economic indicators, is called the technical level of product quality. When economic indicators are taken into account, they talk about the technical and economic level of product quality.

Product quality indicators are the quantitative characteristics of one or more properties of the products that make up its quality, considered in relation to certain conditions of its creation and operation or consumption [8]. 
The main quality indicators include purpose, reliability, manufacturability, standardization, ergonomics, aesthetics, transportability, environmental friendliness and safety.

The authors examined the level of product quality from the point of view of the aggregate of single or complex indicators, as a result of comparing them with basic values, depending on the purpose of the assessment, one can draw the appropriate conclusions. The quality level is assessed by the authors according to a certain scheme. Assessment of the level of product quality for managerial decision-making consists of the following main steps: setting the goal of assessing the level of product quality; the choice of nomenclature, quality indicators of the evaluated and base samples, justification of its necessity and sufficiency; selection or development of a method and techniques for determining the values of quality indicators; selection or determination of the basic values of quality indicators and the search for initial data to determine the actual values of the quality indicators of the evaluated products, the determination of the actual values of the quality indicators and their comparison with the basic.

The following methods for assessing the level of product quality are considered in the article: differential, integrated, mixed, integrated assessment method and expert methods. Each of these methods has a specific field of application, its advantages and disadvantages.

The importance of improving the quality of products for the economy of an organization lies in the fact that it positively affects the efficient use of production resources, the efficient functioning of the organization, as well as its adaptability to the changing conditions of the external economic environment, and activates the process of searching and introducing innovations into production. Improving the quality of products at the macro level contributes to the formation of export potential, which enhances the economic independence of the state, and, consequently, its security. In addition, quality is a catalyst for scientific and technological progress, the welfare of society, etc. Therefore, the state pursues a policy of improving the quality of products that are produced by national enterprises. And also the state pursues a policy of ensuring the competitiveness of products as a condition for achieving sustainable economic development of the national economy. The main areas of improving product quality include improving production technology, improving the organization of production and labor, creating conditions for the sale of goods in a specific market and stimulating quality improvement [9].

\section{Discussion}

Today, product quality is the main component of the efficiency and profitability of the enterprise, therefore it is necessary to pay constant and special attention to it. All participants of the production process from the director of the enterprise to the specific executor of any operation should improve the quality level of the enterprise [10].

Improving product quality is the most important area of intensive economic development, a source of economic growth and the efficiency of social production. The importance of integrated management of product quality and production efficiency increases in these conditions.

Quality management systems that operate at various enterprises are individual. Nevertheless, world science and practice have formed common features of these systems, as well as methods and principles that can be applied in each of them. This article examined the most effective and popular methods that can assess the level of quality of products.

Thus, the level of product quality is a relative characteristic based on a comparison of the values of indicators characterizing the technical and economic excellence of complex indicators of reliability and safety of use of the evaluated products. 
The lack of economic efficiency of improving the level of product quality practically does not exist. Even enterprises or companies that produce non-high-quality products may be interested in improving quality. This always means conquering new markets, expanding production, increasing profits and increasing competitiveness. At the moment, there is the possibility of modernizing production and improving product quality for all existing indicators. There are enterprises for which improving product quality is a secondary concern. However, the conditions of competition in the world market determine that such enterprises will sooner or later be forced to modernize their production and direct the work of the enterprise to improve its quality management system.

In conclusion, we can say that improving the quality of products will always be a positive and cost-effective factor in the development of any enterprise.

\section{References}

1. ISO 31000. Risk management - Principles and guidelines, International Organization for Standardization, 2018

2. ISO 19011:2018. Guidelines for auditing management systems, International Organization for Standardization, 2018

3. ISO 45001:2018. Occupational health and safety management systems - Requirements with guidance for use, International Organization for Standardization, 2018

4. ISO 14001:2015. Environmental management systems - A practical guide for SMEs, International Organization for Standardization, 2015

5. ISO/IEC 27001:2013. Information technology. Security techniques. Information security management systems. Requirements, International Organization for Standardization, 2013

6. ISO 9001:2015. Quality management systems - Requirements, International Organization for Standardization, 2015

7. I.I. Livshitz, P.A. Lontsikh, E.P. Kunakov, V.V. Semenov, Y.V. Kibirev, International Conference "Quality Management, Transport and Information Security, Information Technologies" (IT\&QM\&IS), (2019). DOI: 10.1109/ITQMIS.2019.8928361.

8. I.I. Livshitz, P.A. Lontsikh, N.P. Lontsikh, S.N. Karasev, E. Golovina, International Conference "Quality Management, Transport and Information Security, Information Technologies" (IT\&QM\&IS), (2019). DOI: 10.1109/ITQMIS.2019.8928349

9. S.V. Eliseev, I.I. Livshitz, P.A. Lontsikh, S.N. Karasev, International Conference "Quality Management, Transport and Information Security, Information Technologies" (IT\&QM\&IS), (2019). DOI: 10.1109/ITQMIS.2019.8928376

10. S.V. Eliseev, I.I. Livshitz, P.A. Lontsikh, O.M. Stefanovskaya, International Conference "Quality Management, Transport and Information Security, Information Technologies" (IT\&QM\&IS), (2019). DOI: 10.1109/ITQMIS.2019.8928403

11. I.I. Livshitz, P.A. Lontsikh, O.M. Stefanovskay, E.Y. Golovina, Y.V. Kibirev, International Conference "Quality Management, Transport and Information Security, Information Technologies" (IT\&QM\&IS), (2019). DOI: 10.1109/ITQMIS.2019.8928308

12. O.M. Stefanovskaya, P.A. Lontsykh, V.Y. Konyukhov, Yu.V. Kibirev, International Scientific Conference "Information Society: Health, Economics and Law», (2019). DOI: 10.34648/SIDPO.2019.34.76.040

13. A.V. Vladimirtsev, E.Y. Golovina, V. Kayi, N.P. Lontsikh, O.M. Stefanovskaya, International Conference "Quality Management, Transport and Information Security, 
Information Technologies"

$(I T \& Q M \& I S)$,

(2019).

DOI:

10.1109/ITQMIS.2019.8928371

14. I.I. Livshitz, P.A. Lontsikh, E.P. Kunakov, N.P. Lontsikh, L.I. Tatarnikova, International Conference "Quality Management, Transport and Information Security, Information Technologies" 10.1109/ITQMIS.2019.8928452

15. P.A. Lontsikh, V.A. Moskvitina, E.Y. Golovina, Yu.V. Kibirev, University News. Investments. Construction. The property 9(1), 10-25 (2019). DOI: http://dx.doi.org/10.21285/2227-2917-2019-1-10-25 